\title{
醏
}

Subdirección General de Evaluación de Instrumentos de Politica Comercial*

\section{LA EVOLUCIÓN DEL COMERCIO EXTERIOR POR CARACTERÍSTICAS DE LA EMPRESA}

Los datos de comercio exterior de Aduanas por características de la empresa permiten conocer más detalles de quienes realizan exportaciones e importaciones en nuestro país. El número de asalariados de la empresa, el sector CNAE en el que quedan clasificadas sus actividades o el número de países con el que realizan transacciones son variables interesantes cuyo análisis posibilita obtener conclusiones y afinar las políticas de apoyo a la internacionalización.

Palabras clave: empresa, exportaciones, importaciones, número de asalariados, DIRCE, pyme. Clasificación JEL: F11, F14.

\section{Introducción: datos de comercio exterior por características de la empresa de Aduanas}

Para conocer las características de los operadores de comercio exterior de forma desagregada es necesario acudir a la fuente principal que los elabora en nuestro país. Así, el Departamento de Aduanas e Impuestos Especiales de la Agencia Tributaria (Aduanas) es la institución responsable de realizar esta nueva estadística desde 2010. Los últimos datos disponibles son los correspondientes a 2012 y a 2013 y se hicieron públicos el 15 de septiembre de 2015.

Para producir esta estadística, Aduanas cruza los datos de comercio exterior con el Directorio Central de Empresas (DIRCE) elaborado por el Instituto Nacional de Estadística (INE), utilizando como identificador común el número de identificación fiscal (NIF) del obligado estadístico. De esta forma, se aplican las variables de clasificación del DIRCE (estrato de asalariados, actividad económica

\footnotetext{
* Secretaría de Estado de Comercio. Ministerio de Economía y Competitividad.

Versión de octubre de 2015.
}

principal...) a las empresas que realizan operaciones de comercio exterior. No obstante, conviene resaltar que el ámbito de empresas DIRCE es más limitado que el de los operadores de comercio exterior, ya que el DIRCE es un registro de las empresas españolas que cubre todas las actividades económicas excepto la producción agraria y pesquera, los servicios administrativos de la Administración Central, Autónómica y Local (incluida la Seguridad Social), las actividades de las comunidades de propietarios y el servicio doméstico. Por su parte, en las estadísticas de comercio exterior la determinación del responsable del suministro de la información difiere si se trata de operaciones intracomunitarias (sistema Intrastat) o extracomunitarias (sistema Extrastat). En el primer caso, el obligado a suministrar la información es la persona física o jurídica sujeta al Impuesto sobre el Valor Añadido y que haya formalizado el contrato cuyo efecto sea la expedición o introducción de las mercancías. Sin embargo, en el sistema Extrastat está obligado a presentar la declaración aduanera toda persona física y jurídica que intervenga en actos a los que les sea de aplicación la legislación aduanera. Sirva como ejemplo que en 2013 Aduanas $\triangleright$ 
detectó que 151.160 operadores habían realizado operaciones de exportación (o expedición), de los cuales tan sólo ha podido cruzar con el DIRCE 95.139 empresas. No obstante, estas $95.139 \mathrm{em}-$ presas DIRCE fueron responsables del 90,9 por 100 de las exportaciones declaradas $(214.258,0$ millones de euros sobre el total de $235.814,1 \mathrm{mi}-$ llones).

Es importante destacar que la existencia de un umbral de exención para la declaración estadística del comercio intracomunitario $(250.000$ euros en los años a los que hace referencia este informe, 400.000 euros desde el 1 de enero de 2015) hace que no estén recogidas en esta estadística un gran número de empresas y otros operadores que realizan operaciones intracomunitarias de bajo importe que, en cambio, sí quedan recogidas en el caso del comercio con terceros países. No obstante, el valor que queda excluido es relativamente pequeño, precisamente por tratarse de operadores que comercian por valores bajos con el exterior.

\section{Evolución general de los operadores que realizan exportaciones}

Según las últimas estadísticas elaboradas por Aduanas, en 2013 realizaron operaciones de exportación de comercio declarado en España 151.160 operadores, un 38,2 por 100 más que en 2010, por valor de 235.814,1 millones de euros, un 26,3 por 100 más que en 2010 (Cuadro 1).

De estos, el número de operadores que realizó exportaciones a la Unión Europea (expediciones) registradas por Intrastat se incrementó en un 11,0 por 100 en el periodo $2010-2013$ hasta los 32.662, mientras que los que exportaron al resto del mundo crecieron mucho más, un 42,5 por 100, hasta los 139.072 operadores. En cuanto al valor exportado, los crecimientos están en línea con el incremento de operadores, un 17,0 por 100 para el comercio Intrastat y un 45,6 por 100 para las exportaciones extracomunitarias.

De los 151.160 exportadores en 2013, Aduanas ha podido cruzar con el DIRCE 95.139 empresas a través del NIF, un 32,1 por 100 más que en 2010 y el 62,9 por 100 del total de operadores, si bien representaron el 90,9 por 100 del comercio declarado, 214.258,0 millones de euros sobre el total de $235.814,1$ millones, un 24,4 por 100 más que en 2010.

Comparando los datos del total de operadores del comercio declarado y de los operadores que han podido ser cruzados por el DIRCE (empresas DIRCE), se destaca que, mientras que en 2013 el 89,6 por 100 de los operadores con exportaciones Intrastat eran empresas DIRCE, tan solo el 61,6 por 100 de los operadores con operaciones al resto del mundo lo eran. Ello es debido a que la obligación de presentación de Intrastat sólo se aplica a operadores con operaciones por encima de un determinado umbral de exención (250.000 euros anuales en el periodo analizado), mientras que en las operaciones Extrastat están obligados a presentar un Documento Único Administrativo (DUA) todos aquellos operadores que intervengan en actos en los que les sea de aplicación la legislación aduanera.

En referencia a los operadores regulares (estables en terminología de Aduanas), que son aquellos que han exportado en el año de referencia y en cada uno de los tres años precedentes, el porcentaje de las empresas DIRCE es superior, un 93,3 por 100 en 2013 (38.419 empresas DIRCE regulares sobre 41.168 operadores regulares) y representan el 92,7 por 100 del valor exportado por los operadores regulares. Entre 2010 y 2013 el número de exportadores regulares ha aumentado un 6,2 por 100, mientras que el de las empresas exportadoras DIRCE regulares lo ha hecho en un 8,4 por 100 .

\section{Evolución de los exportadores por tramo de asalariados}

En 2013, prácticamente dos terceras partes del número total de empresas exportadoras DIRCE en España $(65,7$ por 100$)$ tenían menos de $10 \triangleright$ 


\section{LA EVOLUCIÓN DEL COMERCIO EXTERIOR POR CARACTERÍSTICAS DE LA EMPRESA}

\begin{tabular}{|c|c|c|c|c|c|c|c|c|c|c|}
\hline \multicolumn{11}{|c|}{$\begin{array}{c}\text { CUADRO } 1 \\
\text { EXPORTACIONES. NÚMERO DE OPERADORES DIRCE }\end{array}$} \\
\hline & \multicolumn{5}{|c|}{ Número de operadores } & \multicolumn{5}{|c|}{ Valor (miles de euros) } \\
\hline & 2010 & 2011 & 2012 & 2013 & var. $2013 / 2010$ & 2010 & 2011 & 2012 & 2013 & var. $2013 / 2010$ \\
\hline Total... & 109.363 & 123.128 & 137.528 & 151.160 & $38,2 \%$ & 186.780 .070 & 215.230.371 & 226.114.594 & 235.814 .069 & $26,3 \%$ \\
\hline 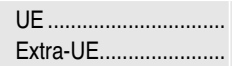 & $\begin{array}{l}29.435 \\
97.607\end{array}$ & $\begin{array}{r}29.870 \\
111.784\end{array}$ & $\begin{array}{r}31.088 \\
125.995\end{array}$ & $\begin{array}{r}32.662 \\
139.072\end{array}$ & $\begin{array}{l}11,0 \% \\
42,5 \%\end{array}$ & $\begin{array}{r}126.290 .977 \\
60.489 .094\end{array}$ & $\begin{array}{r}142.359 .261 \\
72.871 .110\end{array}$ & $\begin{array}{r}142.999 .747 \\
83.114 .847\end{array}$ & $\begin{array}{r}147.721 .563 \\
88.092 .506\end{array}$ & $\begin{array}{l}17,0 \% \\
45,6 \%\end{array}$ \\
\hline Total DIRCE................. & 72.047 & 83.725 & 91.409 & 95.139 & $32,1 \%$ & 172.255 .469 & 198.767.659 & 209.487.958 & 214.257.982 & $24,4 \%$ \\
\hline 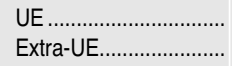 & $\begin{array}{l}26.142 \\
62.880\end{array}$ & $\begin{array}{l}27.001 \\
74.698\end{array}$ & $\begin{array}{l}28.233 \\
82.195\end{array}$ & $\begin{array}{l}29.264 \\
85.713\end{array}$ & $\begin{array}{l}11,9 \% \\
36,3 \%\end{array}$ & $\begin{array}{r}116.524 .490 \\
55.730 .979\end{array}$ & $\begin{array}{r}130.320 .027 \\
68.447 .632\end{array}$ & $\begin{array}{r}131.816 .480 \\
77.671 .478\end{array}$ & $\begin{array}{r}133.750 .823 \\
80.507 .159\end{array}$ & $\begin{array}{l}14,8 \% \\
44,5 \%\end{array}$ \\
\hline DIRCE sobre total ......... & $65,9 \%$ & $68,0 \%$ & $66,5 \%$ & $62,9 \%$ & $-2,9$ p.p. & $92,2 \%$ & $92,4 \%$ & $92,6 \%$ & $90,9 \%$ & $-1,4$ p.p. \\
\hline $\begin{array}{l}\text { UE } \ldots \ldots \ldots \ldots \ldots \ldots \ldots \ldots \ldots \ldots \\
\text { Extra-UE } \ldots \ldots \ldots \ldots \ldots \ldots \ldots \ldots \ldots \ldots \ldots \ldots \ldots\end{array}$ & $\begin{array}{l}88,8 \% \\
64,4 \%\end{array}$ & $\begin{array}{l}90,4 \% \\
66,8 \%\end{array}$ & $\begin{array}{l}90,8 \% \\
65,2 \%\end{array}$ & $\begin{array}{l}89,6 \% \\
61,6 \%\end{array}$ & $\begin{array}{l}0,8 \text { p.p. } \\
-2,8 \text { p.p. }\end{array}$ & $\begin{array}{l}92,3 \% \\
92,1 \%\end{array}$ & $\begin{array}{l}91,5 \% \\
93,9 \%\end{array}$ & $\begin{array}{l}92,2 \% \\
93,5 \%\end{array}$ & $\begin{array}{l}90,5 \% \\
91,4 \%\end{array}$ & $\begin{array}{l}-1,7 \text { p.p. } \\
-0,7 \text { p.p. }\end{array}$ \\
\hline
\end{tabular}

\begin{tabular}{|c|c|c|c|c|c|c|c|c|c|c|}
\hline \multicolumn{11}{|c|}{$\begin{array}{c}\text { CUADRO } 2 \\
\text { EXPORTADORES REGULARES }\end{array}$} \\
\hline & \multicolumn{5}{|c|}{ Número } & \multicolumn{5}{|c|}{ Valor (miles de euros) } \\
\hline & 2010 & 2011 & 2012 & 2013 & var. 2013/2010 & 2010 & 2011 & 2012 & 2013 & var. 2013/2010 \\
\hline Total ................................ & 38.763 & 37.253 & 38.373 & 41.168 & $6,2 \%$ & 170.606 .215 & 195.406 .821 & 205.750 .178 & 216.966 .119 & $27,2 \%$ \\
\hline Total DIRCE ................ & 35.428 & 35.983 & 37.008 & 38.419 & $8,4 \%$ & 160.290 .610 & 185.813 .202 & 194.555 .179 & 201.206 .634 & $25,5 \%$ \\
\hline DIRCE sobre total .......... & $91,4 \%$ & $96,6 \%$ & $96,4 \%$ & $93,3 \%$ & 1,9 p.p. & $94,0 \%$ & $95,1 \%$ & $94,6 \%$ & $92,7 \%$ & $-1,2$ p.p. \\
\hline
\end{tabular}

asalariados, aunque representaron únicamente el 10,4 por 100 del valor exportado declarado. En general, se observa que prácticamente la totalidad de las empresas exportadoras en nuestro país son pymes, concretamente el 97,8 por 100 del total en 2013, si bien su peso en el total del volumen de las exportaciones fue del 47,9 por 100 . En el extremo opuesto, las 1.012 empresas con 500 o más asalariados, el 1,1 por 100 del total, exportaron por valor de $92.327,8$ millones, el 43,1 por 100 del comercio declarado por las empresas DIRCE. A pesar de que el porcentaje de las empresas de mayor tamaño se ha reducido dos décimas desde 2010 , su peso en valor ha aumentado en 4,7 puntos porcentuales (Cuadro 3).

Por otro lado, si analizamos la propensión exportadora, es decir, cuántas de las empresas registradas en el DIRCE están realizando operaciones de exportación (Cuadro 4), se puede observar que del total de las microempresas ( 0 a 9 asalariados), en 2013 sólo el 2,08 por 100 declaraba operaciones de exportación, incrementándose significativamente cuando las empresas pasan a tener de 10 a 49 empleados (20,34 por 100 del total exportado) y más aún cuando pasan al siguiente tramo, entre 50 y 199 empleados $(37,85$ por 100 exportado). Ello no impide que para el conjunto de las empresas de menos de 200 asalariados (que aproximaremos al concepto de pyme en terminología de la UE, dado que el INE no distingue ese tramo concreto de tamaño empresarial), el porcentaje siga siendo muy bajo, de manera que sólo el 2,94 por 100 de las pymes registradas en el DIRCE declara actividades de exportación. En cambio, las grandes empresas tienen una vocación exportadora muy superior, realizando este tipo de actividades en 2013 el 49,01 por 100 de las empresas del DIRCE de más de 200 empleados $\triangle$ 


\begin{tabular}{|c|c|c|c|c|c|c|c|c|c|c|}
\hline \multirow{3}{*}{ Tramo de asalariados } & \multicolumn{9}{|c|}{$\begin{array}{c}\text { CUADRO } 3 \\
\text { EXPORTACIONES. EMPRESAS DIRCE POR TRAMO DE ASALARIADOS }\end{array}$} & \\
\hline & \multicolumn{5}{|c|}{ Número de empresas } & \multicolumn{5}{|c|}{ Valor (miles de euros) } \\
\hline & 2010 & 2011 & 2012 & 2013 & $\begin{array}{l}\text { var. 2013/2010 } \\
\text { (porcentaje) }\end{array}$ & 2010 & 2011 & 2012 & 2013 & $\begin{array}{c}\text { var. 2013/2010 } \\
\text { (porcentaje) }\end{array}$ \\
\hline $\begin{array}{l}0 \_9 \text { microempresas } \ldots \ldots \ldots \ldots \ldots . . . \\
10 \_49\end{array}$ & $\begin{array}{l}42.857 \\
20.423\end{array}$ & $\begin{array}{l}52.036 \\
22.100\end{array}$ & $\begin{array}{l}59.253 \\
22.567\end{array}$ & $\begin{array}{l}62.542 \\
23.129\end{array}$ & $\begin{array}{l}45,9 \\
13,2\end{array}$ & $\begin{array}{l}20.509 .875 \\
25.467 .361\end{array}$ & $\begin{array}{l}22.852 .803 \\
29.403 .199\end{array}$ & $\begin{array}{l}22.698 .037 \\
31.229 .541\end{array}$ & $\begin{array}{l}22.371 .014 \\
31.343 .609\end{array}$ & $\begin{array}{r}9,1 \\
23,1\end{array}$ \\
\hline $50 \_199$ & 6.322 & 6.912 & 6.869 & 6.765 & 7,0 & 33.083 .424 & 40.026 .088 & 39.434 .596 & 40.041 .823 & 21,0 \\
\hline 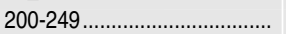 & 530 & 558 & 577 & 563 & 6,2 & 6.678 .344 & 7.079 .121 & 7.850 .709 & 8.860 .723 & 32,7 \\
\hline 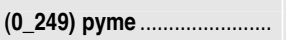 & 70.132 & 81.606 & 89.266 & 92.999 & 32,6 & 85.739 .004 & 99.361 .211 & 101.212 .883 & 102.617.169 & 19,7 \\
\hline $250-499$ & 1.021 & 1.119 & 1.145 & 1.128 & 10,5 & 20.357 .073 & 21.801 .582 & 21.369 .086 & 19.313 .033 & $-5,1$ \\
\hline$>=500$ & 894 & 1.000 & 998 & 1.012 & 13,2 & 66.159 .391 & 77.604 .866 & 86.905 .989 & 92.327 .780 & 39,6 \\
\hline (>250) gran empresa ............. & 1.915 & 2.119 & 2.143 & 2.140 & 11,7 & 86.516 .464 & 99.406 .448 & 108.275 .075 & 111.640 .813 & 29,0 \\
\hline 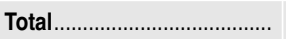 & 72.047 & 83.725 & 91.409 & 95.139 & 32,1 & 172.255 .468 & 198.767659 & 209.487 .958 & 214.257.982 & 24,4 \\
\hline Tramo asalariados & \multicolumn{5}{|c|}{ Número de empresas (porcentaje sobre total) } & \multicolumn{5}{|c|}{ Valor (porcentaje sobre total) } \\
\hline 0_9 microempresas ................ & 59.5 & 62,2 & 64,8 & 65,7 & 6,3 p.p. & 11,9 & 11,5 & 10,8 & 10,4 & $-1,5$ p.p. \\
\hline $10 \_49$ & 28,3 & 26,4 & 24,7 & 24,3 & $-4,0$ p.p. & 14,8 & 14,8 & 14,9 & 14,6 & $-0,2$ p.p. \\
\hline 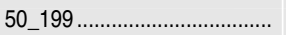 & 8,8 & 8,3 & 7,5 & 7,1 & $-1,7$ p.p. & 19,2 & 20,1 & 18,8 & 18,7 & $-0,5$ p.p. \\
\hline 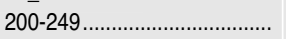 & 0,7 & 0,7 & 0,6 & 0,6 & $-0,1$ p.p. & 3,9 & 3,6 & 3,7 & 4,1 & 0,3 p.p. \\
\hline (0_249) pyme & 97,3 & 97,5 & 97,7 & 97,8 & 0,4 p.p. & 49,8 & 50,0 & 48,3 & 47,9 & $-1,9$ p.p. \\
\hline $250-499$ & 1,4 & 1,3 & 1,3 & 1,2 & $-0,2$ p.p. & 11,8 & 11,0 & 10,2 & 9,0 & $-2,8$ p.p. \\
\hline >=500 & 1,2 & 1,2 & 1,1 & 1,1 & $-0,2$ p.p. & 38,4 & 39,0 & 41,5 & 43,1 & 4,7 p.p \\
\hline (>250) gran empresa ............. & 2.7 & 2,5 & 2,3 & 2,2 & $-0,4$ p.p. & 50,2 & 50,0 & 51,7 & 52,1 & 1,9 p.p. \\
\hline
\end{tabular}

\begin{tabular}{|c|c|c|c|c|c|}
\hline \multirow{3}{*}{ Tramo de asalariados } & \multicolumn{4}{|c|}{$\begin{array}{c}\text { CUADRO } 4 \\
\text { EMPRESAS EXPORTADORAS SOBRE EL TOTAL DE EMPRESAS DIRCE }\end{array}$} & \multirow{3}{*}{ var. $2013 / 2010$} \\
\hline & \multicolumn{4}{|c|}{$\mathrm{N}^{\circ}$ empresas } & \\
\hline & 2010 & 2011 & 2012 & 2013 & \\
\hline \multicolumn{6}{|c|}{ Empresas exportadoras DIRCE } \\
\hline $\begin{array}{l}0 \_9 \\
10 \_49 \ldots \ldots \ldots \ldots \ldots \\
50 \_199 \ldots \ldots \ldots \ldots \ldots \ldots \ldots . . . \\
<200 \text { (pyme) }^{\star}\end{array}$ & $\begin{array}{r}42.857 \\
20.423 \\
6.322 \\
69.602\end{array}$ & $\begin{array}{r}52.036 \\
22.100 \\
6.912 \\
\mathbf{8 1 . 0 4 8}\end{array}$ & $\begin{array}{r}59.253 \\
22.567 \\
6.869 \\
\mathbf{8 8 . 6 8 9}\end{array}$ & $\begin{array}{r}62.542 \\
23.129 \\
6.765 \\
92.436\end{array}$ & $\begin{array}{r}45,9 \% \\
13,2 \% \\
7,0 \% \\
32,8 \%\end{array}$ \\
\hline $200-499 \ldots \ldots \ldots \ldots \ldots \ldots$ & $\begin{array}{r}1.551 \\
894\end{array}$ & $\begin{array}{l}1.677 \\
1.000\end{array}$ & $\begin{array}{r}1.722 \\
998\end{array}$ & $\begin{array}{l}1.691 \\
1.012\end{array}$ & $\begin{array}{r}9,0 \% \\
13,2 \%\end{array}$ \\
\hline Total........................... & 72.047 & 83.725 & 91.409 & 95.139 & $32,1 \%$ \\
\hline \multicolumn{6}{|c|}{ Total empresas DIRCE } \\
\hline $\begin{array}{l}0 \_9 \\
10 \_49 \ldots \ldots \ldots \ldots \ldots \ldots \ldots \ldots \\
50 \_199 \ldots \ldots \ldots \ldots \ldots \ldots \ldots . . \\
<200 \text { (pyme) }^{\star} \ldots \ldots \ldots \ldots . . .\end{array}$ & $\begin{array}{r}3.128 .181 \\
137.161 \\
20.843 \\
3.286 .185\end{array}$ & $\begin{array}{r}3.094 .721 \\
130.994 \\
19.864 \\
3.245 .579\end{array}$ & $\begin{array}{r}3.053 .377 \\
122.183 \\
19.134 \\
3.194 .694\end{array}$ & $\begin{array}{r}3.009 .906 \\
113.710 \\
17.875 \\
3.141 .491\end{array}$ & $\begin{array}{r}-3,8 \% \\
-17,1 \% \\
-14,0 \% \\
-4,0 \%\end{array}$ \\
\hline $200-499 \ldots \ldots \ldots \ldots \ldots \ldots \ldots \ldots$ & $\begin{array}{l}3.374 \\
1.704\end{array}$ & $\begin{array}{l}3.288 \\
1.709\end{array}$ & $\begin{array}{l}3.214 \\
1.709\end{array}$ & $\begin{array}{l}3.450 \\
1.629\end{array}$ & $\begin{array}{r}2,0 \% \\
-4,0 \%\end{array}$ \\
\hline Total............................. & 3.291 .263 & 3.250 .576 & 3.199 .617 & 3.146 .570 & $-4,0 \%$ \\
\hline \multicolumn{6}{|c|}{ Empresas exportadoras DIRCE (porcentaje sobre el total) } \\
\hline $\begin{array}{l}0 \_9 \\
10 \_49 \ldots \ldots \ldots \ldots \ldots \ldots \ldots . . \\
50 \_199 \ldots \ldots \ldots \ldots \ldots \ldots \ldots . . . \\
<200 \text { (pyme) }^{\star} \ldots \ldots \ldots . . .\end{array}$ & $\begin{array}{r}1,37 \\
14,89 \\
30,33 \\
2,12\end{array}$ & $\begin{array}{r}1,68 \\
16,87 \\
34,80 \\
2,50\end{array}$ & $\begin{array}{r}1,94 \\
18,47 \\
35,90 \\
2,78\end{array}$ & $\begin{array}{r}2,08 \\
20,34 \\
37,85 \\
2,94\end{array}$ & $\begin{array}{l}\text { 0,7 p.p. } \\
\text { 5,5 p.p. } \\
\text { 7,5 p.p. } \\
\text { 0,8 p.p. }\end{array}$ \\
\hline $\begin{array}{l}200-499 \ldots \ldots \ldots \ldots \ldots \ldots \ldots \\
>=500\end{array}$ & $\begin{array}{l}45,97 \\
52,46\end{array}$ & $\begin{array}{l}51,00 \\
58,51\end{array}$ & $\begin{array}{l}53,58 \\
58,40\end{array}$ & $\begin{array}{l}49,01 \\
62,12\end{array}$ & $\begin{array}{l}3,0 \text { p.p. } \\
9,7 \text { p.p. }\end{array}$ \\
\hline$\ldots \ldots \ldots . . . . .$. & 2,19 & 2,58 & 2,86 & 3,02 & 0,8 p.p. \\
\hline
\end{tabular}




\section{LA EVOLUCIÓN DEL COMERCIO EXTERIOR POR CARACTERÍSTICAS DE LA EMPRESA}

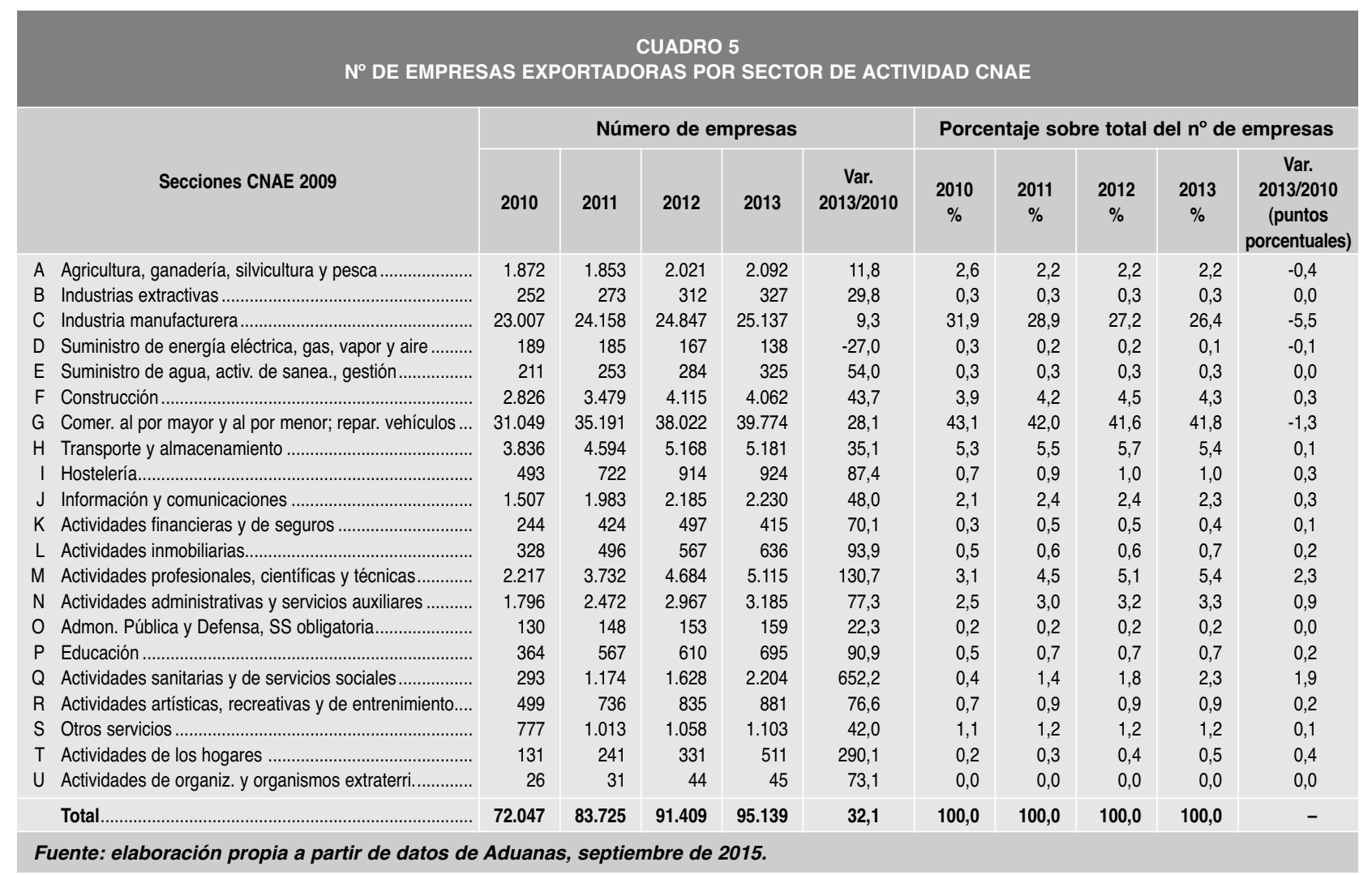

y menos de 499 y hasta el 62,12 por 100 en el caso de las de más de 500 asalariados. No obstante, en todos los tramos de asalariados el porcentaje de empresas exportadoras ha aumentado de 2010 a 2013.

\section{Análisis de la empresa exportadora por actividad económica y estrato de asalariados}

En 2013, el mayor porcentaje de empresas exportadoras DIRCE tuvo como actividad principal el comercio, el 41,8 por 100 del total, seguidas por las empresas de la industria manufacturera, con el 26,4 por 100 del total (Cuadro 5). Con respecto al valor, son las empresas de la industria manufacturera las que más exportan (Cuadro 6). Así, en 2013, exportaron por valor de $147.733,3$ millones de euros, el 69,0 por 100 del comercio declarado por empresas DIRCE, y un 29,3 por 100 más que en 2010.

En términos de número de asalariados, la presencia de las pymes (menos de 250 empleados) es mayoritaria en las exportaciones de todas las actividades, salvo en las de industrias extractivas, industria manufacturera, suministro de energía eléctrica, transporte y almacenamiento, información y comunicaciones y hostelería. En general, como se ve en el Cuadro 7, hay un mayor porcentaje de pymes entre las empresas exportadoras del comercio (98,9 por 100 el total en 2013) que en las de la industria ( 97,2 por 100 del total), y que en el resto de actividades (96,7 por 100). Entre 2010 y 2013, ha habido en casi todos los sectores un aumento de la presencia de pymes en el total de las empresas que exportan, en detrimento de las grandes empresas.

Sin embargo, como se observa en el Cuadro 8, la participación de las pymes en el volumen de exportaciones es muy inferior a su relevancia en cuanto a número en todos los sectores, al contrario que la gran empresa, aunque la diferencia es mayor en la industria, donde la gran empresa representa el 2,8 por 100 del total del número de operadores que exportan pero facturan el 62,1 por 100 del valor total exportado. 


\section{Subdirección General de Evaluación de Instrumentos de Política Comercial}

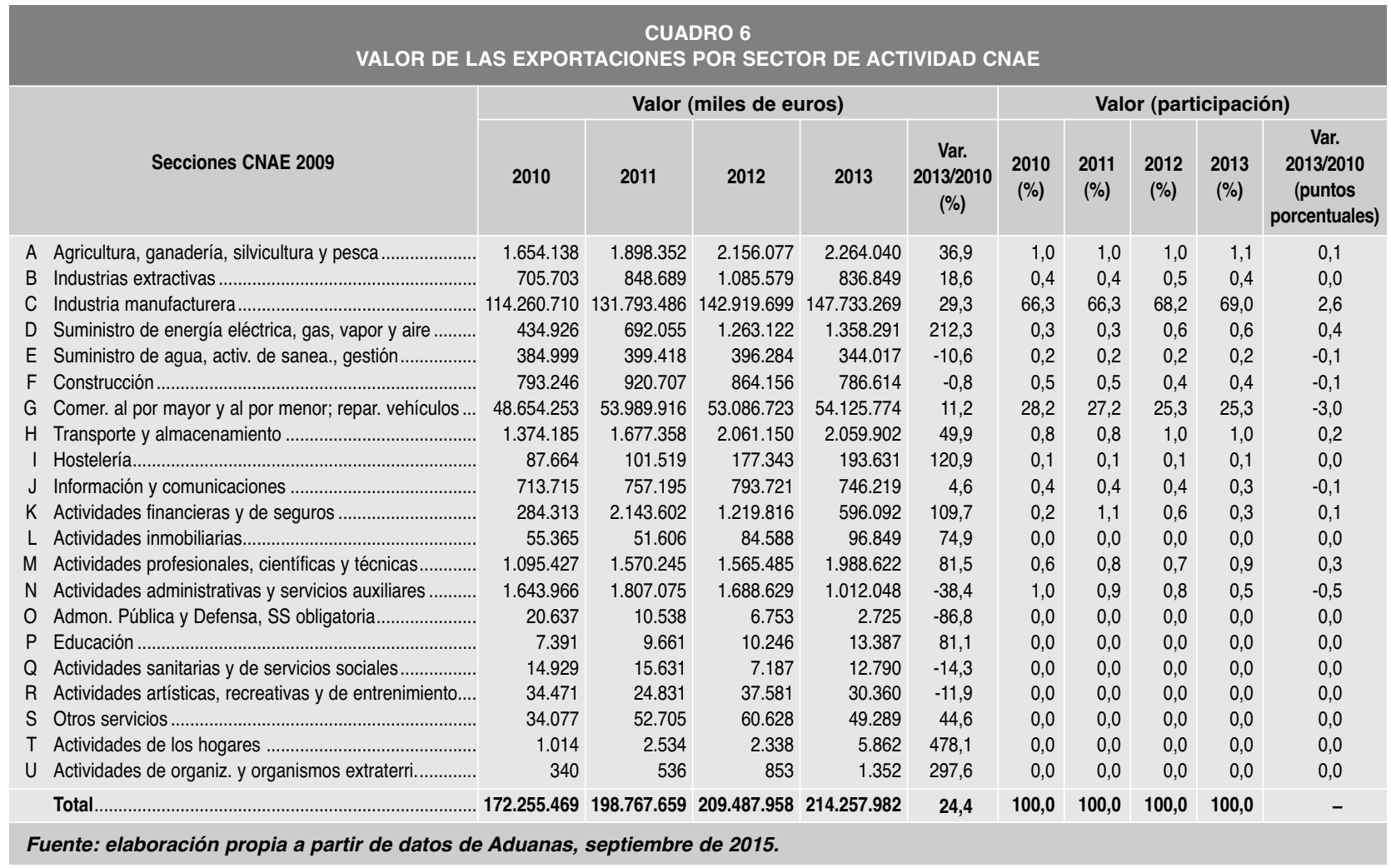

EXPORTACIONES. NÚMERO DE EMPRESAS POR ESTRATO DE ASALARIADOS Y ACTIVIDAD ECONÓMICA

\begin{tabular}{|c|c|c|c|c|c|c|}
\hline \multirow{2}{*}{$\begin{array}{l}\text { Actividad económica } \\
\text { (Secciones CNAE 2009) }\end{array}$} & \multicolumn{3}{|c|}{2010} & \multicolumn{3}{|c|}{2013} \\
\hline & pyme (0-249) & gran empresa $>250$ & Total & pyme (0-249) & gran empresa > 250 & Total \\
\hline $\begin{array}{l}\text { Industria (B, C, D, E) } \\
\text { Comercio (G)..... } \\
\text { Resto }\end{array}$ & $\begin{array}{l}22.853 \\
30.664 \\
16.615\end{array}$ & $\begin{array}{l}806 \\
385 \\
724\end{array}$ & $\begin{array}{l}23.659 \\
31.049 \\
17.339\end{array}$ & $\begin{array}{l}25.195 \\
39.336 \\
28.468\end{array}$ & $\begin{array}{l}732 \\
438 \\
970\end{array}$ & $\begin{array}{l}25.927 \\
39.774 \\
29.438\end{array}$ \\
\hline Total & 70.132 & 1.915 & 72.047 & 92.999 & 2.140 & 95.139 \\
\hline \multicolumn{7}{|c|}{ Porcentaje sobre total actividad } \\
\hline $\begin{array}{l}\text { Industria }(B, C, D, E) \ldots \ldots . . \\
\text { Comercio }(G) \ldots \ldots \ldots \ldots \ldots \ldots \\
\text { Resto } \ldots \ldots \ldots \ldots \ldots \ldots \ldots \ldots \ldots \ldots \ldots\end{array}$ & $\begin{array}{l}96.6 \\
98,8 \\
95,8\end{array}$ & $\begin{array}{l}3,4 \\
1,2 \\
4,2\end{array}$ & $\begin{array}{l}100,0 \\
100,0 \\
100,0\end{array}$ & $\begin{array}{l}97,2 \\
98,9 \\
96,7\end{array}$ & $\begin{array}{l}2,8 \\
1,1 \\
3,3\end{array}$ & $\begin{array}{l}100,0 \\
100,0 \\
100,0\end{array}$ \\
\hline Total .............................. & 97,3 & 2,7 & 100,0 & 97,8 & 2,2 & 100,0 \\
\hline
\end{tabular}

\begin{tabular}{|c|c|c|c|c|c|c|c|c|}
\hline \multirow[b]{3}{*}{$\begin{array}{l}\text { Actividad económica } \\
\text { (Secciones CNAE 2009) }\end{array}$} & \multicolumn{8}{|c|}{$\begin{array}{c}\text { CUADRO } 8 \\
\text { VALOR EXPORTACIONES POR ESTRATO DE ASALARIADOS Y ACTIVIDAD ECONÓMICA } \\
\text { (Miles de euros) }\end{array}$} \\
\hline & \multicolumn{3}{|c|}{2010} & \multicolumn{3}{|c|}{2013} & \multirow{2}{*}{$\begin{array}{c}2010 \\
\text { Total sector } \\
\text { sobre total } \\
\text { exportaciones } \\
\text { (\%) }\end{array}$} & \multirow{2}{*}{$\begin{array}{c}2013 \\
\text { Total sector } \\
\text { sobre total } \\
\text { exportaciones } \\
(\%)\end{array}$} \\
\hline & pyme $(0-249)$ & gran empresa $>250$ & Total & pyme (0-249) & gran empresa $>250$ & Total & & \\
\hline 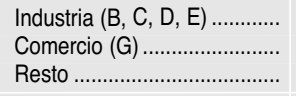 & $\begin{array}{r}45.699 .959 \\
34.685 .406 \\
5.353 .639\end{array}$ & $\begin{array}{c}70.086 .375 \\
13.968 .849 \\
2.461 .240\end{array}$ & $\begin{array}{r}115.786 .338 \\
48.654 .253 \\
7.814 .878\end{array}$ & $\begin{array}{r}57.008 .676 \\
38.921 .879 \\
6.686 .617\end{array}$ & $\begin{array}{r}93.263 .750 \\
15.203 .895 \\
3.173 .165\end{array}$ & $\begin{array}{r}150.272 .426 \\
54.125 .774 \\
9.859 .782\end{array}$ & $\begin{array}{r}67,2 \\
28,2 \\
4,5\end{array}$ & $\begin{array}{r}70,1 \\
25,3 \\
4,6\end{array}$ \\
\hline Total & 85.739 .004 & 86516464 & 172.255 .469 & 102.617 .172 & 111.640 .810 & 214.257.982 & 100,0 & 100,0 \\
\hline \multicolumn{9}{|c|}{ Porcentaje sobre total actividad } \\
\hline $\begin{array}{l}\text { Industria }(B, C, D, E) \\
\text { Comercio }(G) \\
\text { Resto }\end{array}$ & $\begin{array}{l}39,5 \\
71,3 \\
68,5\end{array}$ & $\begin{array}{l}60,5 \\
28,7 \\
31,5\end{array}$ & $\begin{array}{l}100,0 \\
100,0 \\
100,0\end{array}$ & $\begin{array}{l}37,9 \\
71,9 \\
67,8\end{array}$ & $\begin{array}{l}62,1 \\
28,1 \\
32,2\end{array}$ & $\begin{array}{l}100,0 \\
100,0 \\
100,0\end{array}$ & & \\
\hline Total ............................................... & 49,8 & 50,2 & 100,0 & 47,9 & 52,1 & 100,0 & & \\
\hline
\end{tabular}




\section{LA EVOLUCIÓN DEL COMERCIO EXTERIOR POR CARACTERÍSTICAS DE LA EMPRESA}

\begin{tabular}{|c|c|c|c|c|c|c|}
\hline \multirow[b]{3}{*}{$\mathrm{N}^{\circ}$ de empresas } & \multicolumn{2}{|r|}{$\begin{array}{l}\text { CUADRO } 9 \\
\text { COMERCIO }\end{array}$} & TERIOR PO & A DE & 310 & \\
\hline & \multicolumn{3}{|c|}{ Valor (miles de euros) } & \multicolumn{3}{|c|}{ Porcentaje sobre total } \\
\hline & 2010 & 2013 & $\begin{array}{c}\text { Var. 2013/2010 } \\
\text { (porcentaje) }\end{array}$ & 2010 & 2013 & $\begin{array}{l}\text { Var. 2013/2010 } \\
\text { (puntos } \\
\text { porcentuales) }\end{array}$ \\
\hline \multicolumn{7}{|l|}{ Total } \\
\hline 5 principales empresas .................................................. & 20.476 .651 & 23.841 .765 & 16,4 & 11,9 & 11,1 & $-0,8$ \\
\hline 10 principales empresas & 29.613 .321 & 37.435 .573 & 26,4 & 17,2 & 17,5 & 0,3 \\
\hline 20 principales empresas ............................................ & 41.157 .716 & 52.348 .896 & 27,2 & 23,9 & 24,4 & 0,5 \\
\hline 50 principales empresas & 58.581 .272 & 72.428 .396 & 23,6 & 34,0 & 33,8 & $-0,2$ \\
\hline 100 principales empresas & 71.335 .255 & 88.380 .232 & 23,9 & 41,4 & 41,2 & $-0,2$ \\
\hline 500 principales empresas.............................................. & 105.212 .413 & 126.832 .635 & 20,5 & 61,1 & 59,2 & $-1,9$ \\
\hline 1.000 principales empresas....................... & 121.719 .446 & 145.590 .387 & 19,6 & 70,7 & 68,0 & $-2,7$ \\
\hline Todas las empresas & 172.255 .469 & 214.257.982 & 24,4 & 100,0 & 100,0 & - \\
\hline \multicolumn{7}{|c|}{ Unión Europea } \\
\hline 5 principales empresas....... & 14.964 .046 & 13.786 .379 & $-7,9$ & 12,8 & 10,3 & $-2,5$ \\
\hline 10 principales empresas......... & 20.863 .854 & 22.312 .442 & 6,9 & 17,9 & 16,7 & $-1,2$ \\
\hline 20 principales empresas & 27.489 .002 & 31.405 .217 & 14,2 & 23,6 & 23,5 & $-0,1$ \\
\hline 50 principales empresas ................. & 37.470 .793 & 44.132 .525 & 17,8 & 32,2 & 33,0 & 0,8 \\
\hline 100 principales empresas...………………………...... & 45.640 .759 & 53.303 .233 & 16,8 & 39,2 & 39,9 & 0,7 \\
\hline 500 principales empresas............... & 68.358 .653 & 78.659 .353 & 15,1 & 58,7 & 58,8 & 0,1 \\
\hline 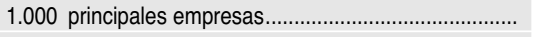 & 79.903 .875 & 91.486 .953 & 14,5 & 68,6 & 68,4 & $-0,2$ \\
\hline Todas las empresas & 116.524 .490 & 133.750 .823 & 14,8 & 100,0 & 100,0 & - \\
\hline \multicolumn{7}{|c|}{ Terceros países } \\
\hline 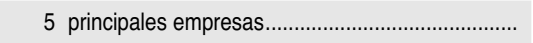 & 5.512 .605 & 11.798 .959 & 114,0 & 9,9 & 14,7 & 4,8 \\
\hline 10 principales empresas $\ldots \ldots \ldots$ & 8.749 .467 & 17.319 .505 & 97,9 & 15,7 & 21,5 & 5,8 \\
\hline 20 principales empresas & 13.668 .713 & 24.423 .066 & 78,7 & 24,5 & 30,3 & 5,8 \\
\hline 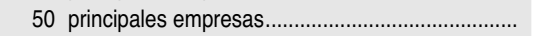 & 21.110 .478 & 33.353 .827 & 58,0 & 37,9 & 41,4 & 3,6 \\
\hline 100 principales empresas ........................................... & 25.694 .496 & 39.840 .275 & 55,1 & 46,1 & 49,5 & 3,4 \\
\hline 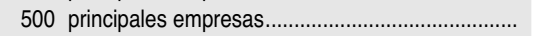 & 36.853 .760 & 54.741 .111 & 48,5 & 66,1 & 68,0 & 1,9 \\
\hline 1.000 principales empresas................ & 41.815 .571 & 61.374 .793 & 46,8 & 75,0 & 76,2 & 1,2 \\
\hline Todas las empresas. & 55.730 .979 & 80.507 .159 & 44,5 & 100,0 & 100,0 & - \\
\hline
\end{tabular}

\section{Análisis de la concentración de las exportaciones por empresas principales}

En 2013, prácticamente un cuarto de las exportaciones declaradas por empresas DIRCE (24,4 por $100)$ fue realizado por las 20 principales empresas exportadoras (Cuadro 9). Concretamente, exportaron por valor de 52.348,9 millones de euros, un 27,2 por 100 más que en 2010 . Por su parte, las 500 principales empresas exportadoras acapararon prácticamente el 60 por 100 de las exportaciones (59,2 por 100), por valor de 126.832,6 millones de euros, un 20,5 por 100 más que en 2010. No obstante, en 2010 la concentración de exportaciones de estas empresas era mayor, el 61,1 por 100. La concentración es más acentuada en las exportaciones a países extracomunitarios que en las ventas a la UE, ya que las 20 principales empresas acaparan en 2013 el 30,3 por 100 de las exportaciones a terceros países y las 500 principales empresas, más de dos terceras partes (68,0 por 100$)$. Por actividades económicas, como se muestra en el Cuadro 10, en 2013 la concentración de exportaciones de las 500 principales empresas en la industria es mayor que en el comercio $(69,5$ por 100 frente a 63,2 por 100).

\section{Análisis de la empresa exportadora por actividad económica y tramo de exportación}

En 2013, más de la mitad de las exportaciones declaradas por empresas DIRCE $(50,6$ por 100 , por valor de 108.465,6 millones de euros), fueron realizadas por las 242 que exportaron ese año $D$ 


\begin{tabular}{|c|c|c|c|c|c|c|c|c|}
\hline \multicolumn{9}{|c|}{$\begin{array}{c}\text { CUADRO } 10 \\
\text { EXPORTACIONES. CONCENTRACIÓN POR NÚMERO DE }\end{array}$} \\
\hline \multirow{2}{*}{$\begin{array}{c}2013 \\
N^{\circ} \text { de empresas }\end{array}$} & \multicolumn{4}{|c|}{ Valor (miles de euros) } & \multicolumn{4}{|c|}{ Porcentaje sobre total } \\
\hline & Industria & Comercio & Resto & Total & Industria & Comercio & Resto & Total \\
\hline 5 principales empresas.................. & 23.841 .765 & 7.475 .811 & 2.391 .328 & 23.841 .765 & 15,9 & 13,8 & 24,3 & 11,1 \\
\hline 10 principales empresas................... & 35.742 .065 & 10.462 .920 & 3.053 .911 & 37.435 .573 & 23,8 & 19,3 & 31,0 & 17,5 \\
\hline 20 principales empresas.................. & 49.151 .870 & 14.362 .523 & 3.782 .397 & 52.348 .896 & 32,7 & 26,5 & 38,4 & 24,4 \\
\hline 50 principales empresas.................. & 64.834 .164 & 19.558 .340 & 4.802 .438 & 72.428 .396 & 43,1 & 36,1 & 48,7 & 33,8 \\
\hline 100 principales empresas................... & 75.914 .918 & 23.773 .724 & 5.733 .398 & 88.380 .232 & 50,5 & 43,9 & 58,1 & 41,2 \\
\hline 500 principales empresas.................... & 104.371 .499 & 34.229 .355 & 7.934 .438 & 126.832 .635 & 69,5 & 63,2 & 80,5 & 59,2 \\
\hline 1.000 principales empresas.................. & 118.513 .404 & 39.428 .370 & 8.745 .543 & 145.590 .387 & 78,9 & 72,8 & 88,7 & 68,0 \\
\hline Todas las empresas ................ & 150.272 .426 & 54.125 .774 & 9.859 .782 & 214.257.982 & 100,0 & 100,0 & 100,0 & 100,0 \\
\hline
\end{tabular}

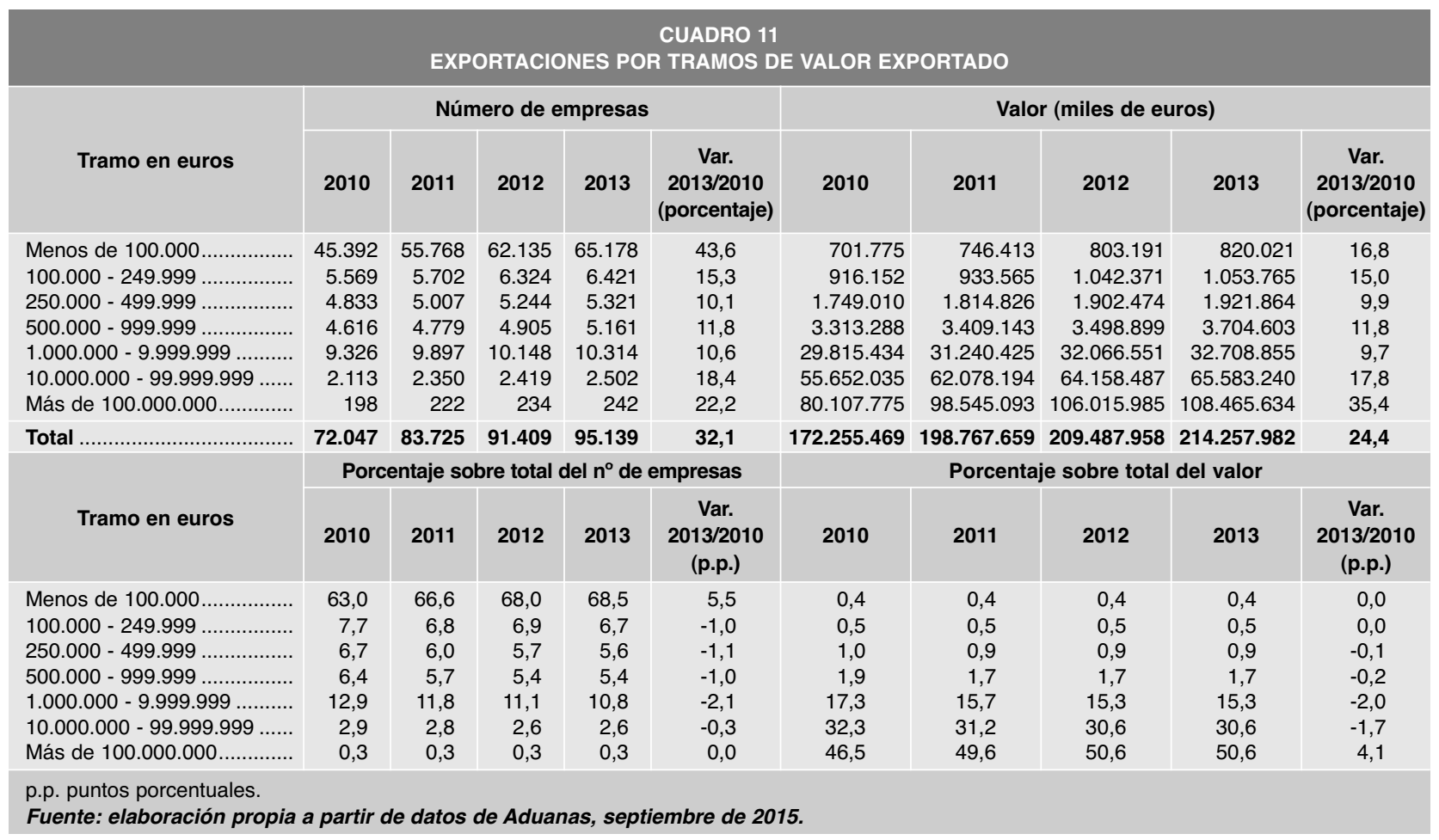

por más de 100 millones de euros, el 0,3 por 100 del total de las empresas.

En el extremo opuesto, más de dos terceras partes de empresas DIRCE $(68,5$ por 100$)$ exportaron menos de 100.000 euros de comercio declarado, lo que supuso únicamente un 0,4 por 100 del valor total de exportaciones declaradas. En 2013, la actividad que concentra más empresas que exportan más de 100 millones de euros es la industria, con 171 empresas de las 242 del conjunto de la economía. Estos grandes exportadores en la industria acaparan más de la mitad $(56,4$ por 100$)$ de las exportaciones industriales (Cuadros 11 y 12).

\section{Análisis de la empresa exportadora por destino geográfico de las exportaciones}

En 2013, 29.264 empresas DIRCE efectuaron exportaciones declaradas hacia la Unión Europea, un 11,9 por 100 más que en 2010 , y concentraron el 62,4 por 100 del comercio declarado total por empresas DIRCE. Por otro lado, el número de las empresas DIRCE que exportan a terceros países es mucho mayor, 85.713 (un 36,3 por 100 más que en 2010), aunque sólo representan el 37,6 por 100 del comercio declarado. El elevado número de $\triangle$ 


\section{LA EVOLUCIÓN DEL COMERCIO EXTERIOR POR CARACTERÍSTICAS DE LA EMPRESA}

\begin{tabular}{|c|c|c|c|c|c|c|c|c|}
\hline \multirow{3}{*}{ Tramo en euros } & \multicolumn{6}{|c|}{$\begin{array}{c}\text { CUADRO } 12 \\
\text { EXPORTACIONES POR TRAMO DE EXPORTACIÓN Y ACTIVIDAD ECONÓMICA (2013) }\end{array}$} & & \\
\hline & \multicolumn{4}{|c|}{ Número de empresas } & \multicolumn{4}{|c|}{ Valor (miles de euros) } \\
\hline & Industria & Comercio & Resto & Total & Industria & Comercio & Resto & Total \\
\hline Menos de $100.000 \ldots \ldots \ldots \ldots$ & 12.784 & 26.502 & 25.892 & 65.178 & 224.936 & 380.750 & 214.335 & 820.021 \\
\hline $100.000-249.999 \ldots \ldots \ldots \ldots$ & 2.170 & 3.131 & 1.120 & 6.421 & 357.091 & 514.128 & 182.546 & 1.053 .765 \\
\hline 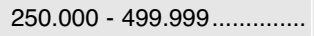 & 1.919 & 2.568 & 834 & 5.321 & 690.883 & 935.103 & 295.878 & 1.921 .864 \\
\hline $500.000-999.999 \ldots \ldots \ldots \ldots \ldots$ & 2.165 & 2.401 & 595 & 5.161 & 1.565 .431 & 1.714 .696 & 424.476 & 3.704 .603 \\
\hline $1.000 .000-9.999 .999 \ldots \ldots \ldots$ & 5.044 & 4.409 & 861 & 10.314 & 16.910 .315 & 13.215 .557 & 2.582 .983 & 32.708 .855 \\
\hline $10.000 .000-99.999 .999 \ldots$. & 1.674 & 703 & 125 & 2.502 & 45.836 .736 & 16.744.339 & 3.002 .165 & 65.583 .240 \\
\hline Más de $100.000 .000 \ldots \ldots \ldots . .$. & 171 & 60 & 11 & 242 & 84.687 .034 & 20.621 .201 & 3.157 .399 & 108.465 .634 \\
\hline Total ................. & 25.927 & 39.774 & 29.438 & 95.139 & 150.272 .426 & 54.125 .774 & 9.859 .782 & 214.257.982 \\
\hline Tramo en euros & \multicolumn{4}{|c|}{ Porcentaje sobre total del número de empresas } & \multicolumn{4}{|c|}{ Porcentaje sobre el total del valor } \\
\hline Menos de $100.000 \ldots \ldots \ldots \ldots$ & 49,3 & 66,6 & 88,0 & 68,5 & 0,1 & 0,7 & 2,2 & 0,4 \\
\hline $100.000-249.999 \ldots \ldots \ldots \ldots \ldots$ & 8,4 & 7,9 & 3,8 & 6,7 & 0,2 & 0,9 & 1,9 & 0,5 \\
\hline $250.000-499.999 \ldots \ldots \ldots \ldots . . . .$. & 7,4 & 6,5 & 2,8 & 5,6 & 0,5 & 1,7 & 3,0 & 0,9 \\
\hline $500.000-999.999 \ldots \ldots \ldots \ldots . . . .$. & 8,4 & 6,0 & 2,0 & 5,4 & 1,0 & 3,2 & 4,3 & 1,7 \\
\hline $1.000 .000-9.999 .999 \ldots \ldots \ldots$ & 19,5 & 11,1 & 2,9 & 10,8 & 11,3 & 24,4 & 26,2 & 15,3 \\
\hline $10.000 .000-99.999 .999 \ldots$. & 6,5 & 1,8 & 0,4 & 2,6 & 30,5 & 30,9 & 30,4 & 30,6 \\
\hline Más de $100.000 .000 \ldots \ldots \ldots . . .$. & 0,7 & 0,2 & 0,0 & 0,3 & 56,4 & 38,1 & 32,0 & 50,6 \\
\hline
\end{tabular}

empresas DIRCE que exportan a países terceros en comparación con el número de empresas DIRCE que exportan a la Unión Europea, está claramente sesgado por el hecho que las empresas DIRCE que no llegan al umbral de exención en el comercio intracomunitario no quedan recogidos en estas estadísticas.

En 2013, el 90,1 por 100 de las empresas exportadoras DIRCE vendieron a países terceros, siendo un 2,8 puntos porcentuales más que en 2010. Por destinos geográficos, cabe destacar que el 24,1 por 100 de las empresas exportadoras DIRCE vendieron a América del Sur, 4,1 puntos porcentuales más que en 2010. AAmérica del Norte exportaron un 22,6 por 100, 5,6 puntos más que en 2010.

Se observa que las exportaciones en este periodo han crecido hacia áreas geográficas no europeas en cuanto a número de empresas y valor exportado. Sin embargo, aunque la mayoría de empresas exporte hacia países no europeos, más de las mitad del valor exportado es comercio intracomunitario (Cuadro 13, en página siguiente).

\section{Número de empresas por países a los que se exporta y zona de intercambio}

En 2013, 5.367 empresas, el 5,6 por 100 del total de empresas exportadoras DIRCE, exportaron a
20 o más países, un 36,5 por 100 más que en 2010. Por valor exportado, estas empresas acapararon el 67,2 por 100 del valor total exportado, 6,0 puntos porcentuales (pp) más que en 2010.

En cambio, un 52,6 por 100 de las empresas solo exportó a un país en 2013 , representando sólo un 3,2 por 100 del valor total exportado. Teniendo en cuenta únicamente los destinos comunitarios, el 30,6 por 100 exporta a solo un país, representando un 5,1 por 100 del valor total exportado a la Unión Europea, mientras que el 2,9 por 100 exporta a 20 países o más, representando el 23,3 por 100 del valor total exportado a la Unión Europea (3,5 pp más que en 2010).

Sin embargo, el número de empresas que exportan hacia un único país fuera de la Unión Europea aumenta hasta el 56,9 por 100 del total de empresas, aunque con un 4,7 por 100 del total del valor exportado a destinos extracomunitarios. Por otro lado, el 3,2 por 100 de las empresas exportan a 20 países o más de fuera de la Unión Europea, pero representan el 61,2 por 100 del valor total exportado a países no pertenecientes a la Unión Europea, 10,9 pp más que en 2010.

Se observa que en el extremo de empresas que exportan a 20 países o más, el valor exportado sobre el total de cada área es muy dispar entre los dos destinos (23,3 por 100 en el comercio $D$ 


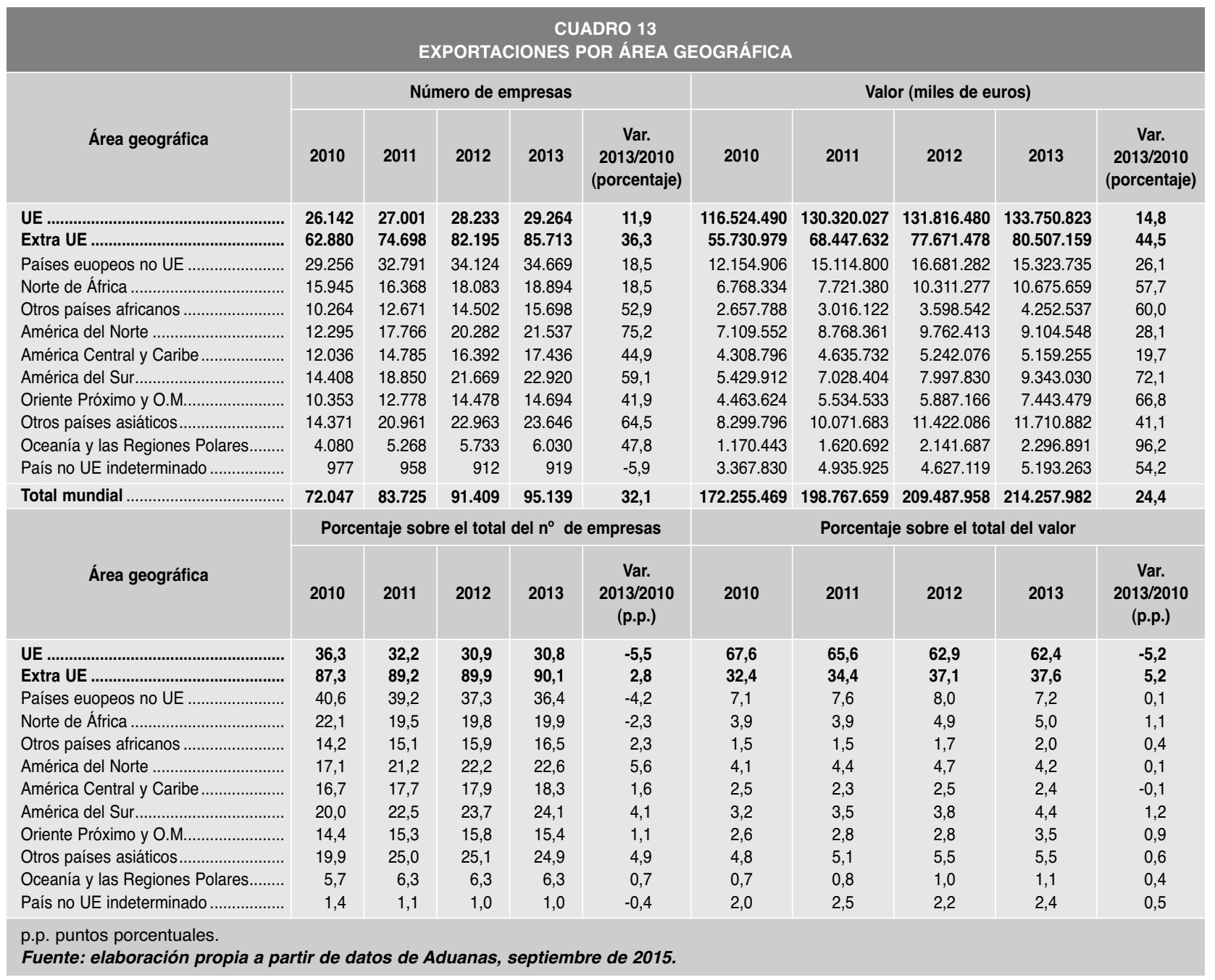

intracomunitario y 61,2 por 100 en el comercio extracomunitario), a pesar del que el porcentaje del número de empresas sea aproximadamente el mismo, en torno al 3 por 100. A su vez, la participación del número de empresas que exportan a un solo país cambia radicalmente dependiendo de donde sea el destino, prácticamente el doble en el comercio extraUE que en el intra-UE (30,6 por 100 en el comercio intracomunitario y 56,9 por 100 en el comercio extracomunitario). Sin embargo, el valor exportado sobre el total es muy parejo, siendo aproximadamente del 5 por 100 en ambos casos (Cuadros 14 y 15).

\section{Comparativa con la UE de empresas exportadoras por número de asalariados}

Si analizamos los últimos datos equivalentes a los recientemente publicados por Aduanas para el conjunto de los países miembros de la UE-28 ${ }^{1}$ para 2013, observamos que el 97,9 por 100 de las empresas exportadoras de la UE, como media, son pymes $^{2}$, porcentaje equivalente al caso español (97,8 por 100). En casi todos los países el dato es similar, con alguna excepción como Letonia, donde el porcentaje de pymes dentro del total de empresas exportadoras es del 92,7 por 100.

Tampoco hay grandes diferencias en cuanto a la presencia de microempresas (de 0 a 9 asalariados), estando el caso español $(65,7$ por 100) cerca de la media de la UE-28 (66,3 por 100), igual que Italia $(65,6$ por 100$)$ y algo por encima de Francia $(64,7$ por $100)$ y Reino Unido (64,8 por 100). Es destacable, $\square$

\footnotetext{
1 Datos Eurostat, septiembre de 2015.

2 Atendiendo sólo al número de asalariados, sin tener en cuenta el volumen de facturación o el balance.
} 


\section{LA EVOLUCIÓN DEL COMERCIO EXTERIOR POR CARACTERÍSTICAS DE LA EMPRESA}

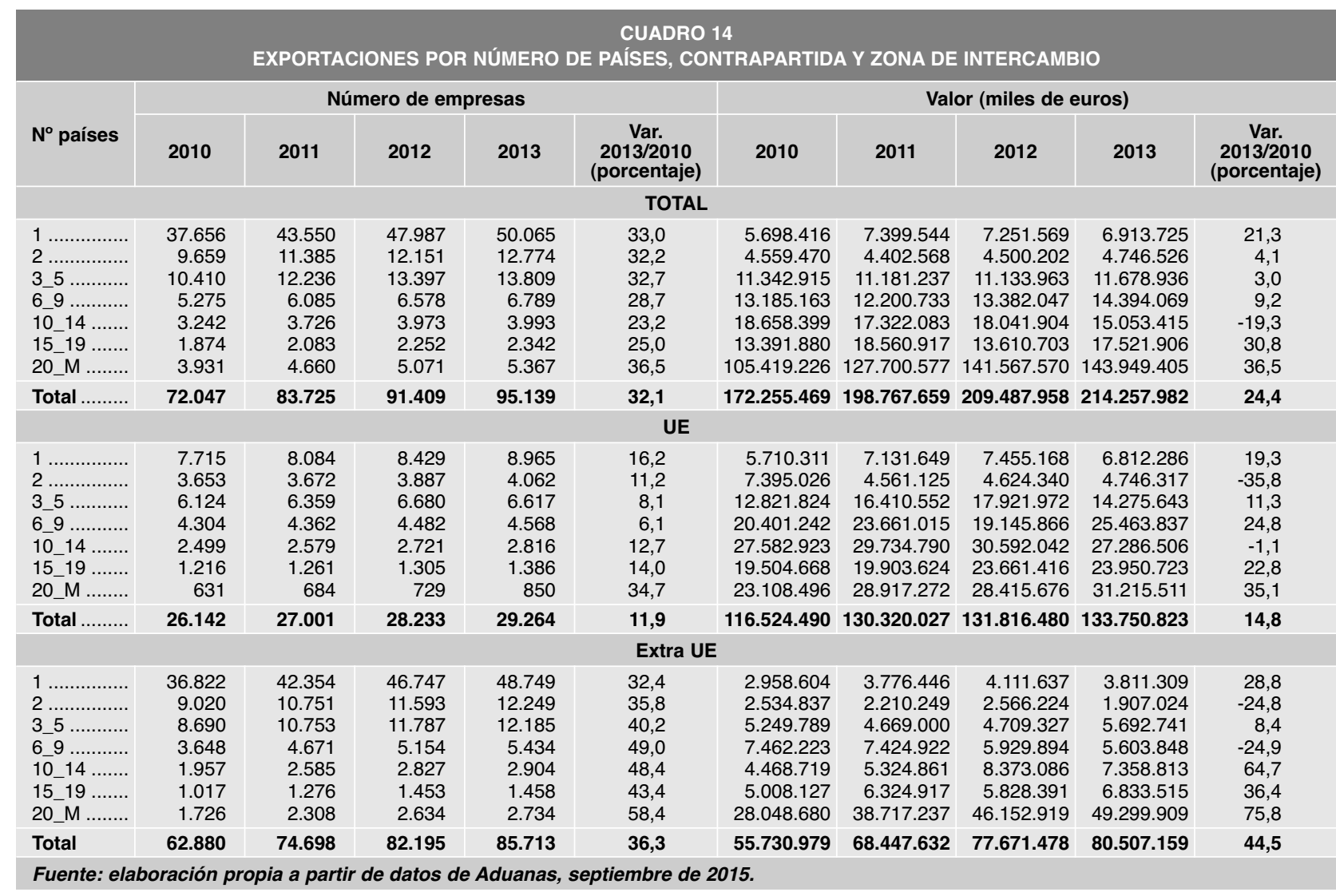

\begin{tabular}{|c|c|c|c|c|c|c|c|c|c|c|}
\hline \multirow[b]{3}{*}{$N^{\circ}$ países } & \multicolumn{9}{|c|}{$\begin{array}{l}\text { CUADRO } 15 \\
\text { EXPORTACIONES POR NÚMERO DE PAÍSES Y ZONA DE INTERCAMBIO } \\
\text { (Porcentaje sobre total) }\end{array}$} & \\
\hline & \multicolumn{5}{|c|}{ Porcentaje sobre el número de empresas } & \multicolumn{5}{|c|}{ Porcentaje sobre el total del valor } \\
\hline & 2010 & 2011 & 2012 & 2013 & $\begin{array}{l}\text { Var. } \\
2013 / 2010 \\
\text { (p.p.) }\end{array}$ & 2010 & 2011 & 2012 & 2013 & $\begin{array}{l}\text { Var. } \\
\text { 2013/2010 } \\
\text { (p.p.) }\end{array}$ \\
\hline \multicolumn{11}{|c|}{ TOTAL } \\
\hline 1 ………....... & 52,3 & 52,0 & 52,5 & 52,6 & 0,4 & 3,3 & 3,7 & 3,5 & 3,2 & $-0,1$ \\
\hline $2 \ldots \ldots \ldots \ldots \ldots$ & 13,4 & 13,6 & 13,3 & 13,4 & 0,0 & 2,6 & 2,2 & 2,1 & 2,2 & $-0,4$ \\
\hline 3_5 …….... & 14,4 & 14,6 & 14,7 & 14,5 & 0,1 & 6,6 & 5,6 & 5,3 & 5,5 & $-1,1$ \\
\hline 6_9 ……...... & 7,3 & 7,3 & 7,2 & 7,1 & $-0,2$ & 7,7 & 6,1 & 6,4 & 6,7 & $-0,9$ \\
\hline $10 \_14 \ldots \ldots$ & 4,5 & 4,5 & 4,3 & 4,2 & $-0,3$ & 10,8 & 8,7 & 8,6 & 7,0 & $-3,8$ \\
\hline $15 \_19 \ldots \ldots$ & 2,6 & 2,5 & 2,5 & 2,5 & $-0,1$ & 7,8 & 9,3 & 6,5 & 8,2 & 0,4 \\
\hline 20_M ......... & 5,5 & 5,6 & 5,5 & 5,6 & 0,2 & 61,2 & 64,2 & 67,6 & 67,2 & 6,0 \\
\hline Total ........... & 100,0 & 100,0 & 100,0 & 100,0 & - & 100,0 & 100,0 & 100,0 & 100,0 & - \\
\hline \multicolumn{11}{|c|}{ UE } \\
\hline 1 ………........ & 29,5 & 29,9 & 29,9 & 30,6 & 1,1 & 4,9 & 5,5 & 5,7 & 5,1 & 0,2 \\
\hline $2 \ldots \ldots \ldots \ldots . .$. & 14,0 & 13,6 & 13,8 & 13,9 & $-0,1$ & 6,3 & 3,5 & 3,5 & 3,5 & $-2,8$ \\
\hline 3_5 …....... & 23,4 & 23,6 & 23,7 & 22,6 & $-0,8$ & 11,0 & 12,6 & 13,6 & 10,7 & $-0,3$ \\
\hline 6_9 ............ & 16,5 & 16,2 & 15,9 & 15,6 & $-0,9$ & 17,5 & 18,2 & 14,5 & 19,0 & 1,5 \\
\hline $10 \_14 \ldots \ldots$ & 9,6 & 9,6 & 9,6 & 9,6 & 0,1 & 23,7 & 22,8 & 23,2 & 20,4 & $-3,3$ \\
\hline $15 \_19 \ldots \ldots$. & 4,7 & 4,7 & 4,6 & 4,7 & 0,1 & 16,7 & 15,3 & 18,0 & 17,9 & 1,2 \\
\hline $20 \_M$......... & 2,4 & 2,5 & 2,6 & 2,9 & 0,5 & 19,8 & 22,2 & 21,6 & 23,3 & 3,5 \\
\hline Total .......... & 100,0 & 100,0 & 100,0 & 100,0 & - & 100,0 & 100,0 & 100,0 & 100,0 & - \\
\hline \multicolumn{11}{|c|}{ Extra UE } \\
\hline 1 .............. & 58,6 & 56,7 & 56,9 & 56,9 & $-1,7$ & 5,3 & 5,5 & 5,3 & 4,7 & $-0,6$ \\
\hline 2 ……...... & 14,3 & 14,4 & 14,1 & 14,3 & $-0,1$ & 4,5 & 3,2 & 3,3 & 2,4 & $-2,2$ \\
\hline 3_5 ……... & 13,8 & 14,4 & 14,3 & 14,2 & 0,4 & 9,4 & 6,8 & 6,1 & 7,1 & $-2,3$ \\
\hline 6_9 ……........ & 5,8 & 6,3 & 6,3 & 6,3 & 0,5 & 13,4 & 10,8 & 7,6 & 7,0 & $-6,4$ \\
\hline $10 \_14 \ldots \ldots$. & 3,1 & 3,5 & 3,4 & 3,4 & 0,3 & 8,0 & 7,8 & 10,8 & 9,1 & 1,1 \\
\hline $15 \_19 \ldots \ldots$. & 1,6 & 1,7 & 1,8 & 1,7 & 0,1 & 9,0 & 9,2 & 7,5 & 8,5 & $-0,5$ \\
\hline $20 \mathrm{M} \ldots \ldots . . .$. & 2,7 & 3,1 & 3,2 & 3,2 & 0,4 & 50,3 & 56,6 & 59,4 & 61,2 & 10,9 \\
\hline Total ............. & 100,0 & 100,0 & 100,0 & 100,0 & - & 100,0 & 100,0 & 100,0 & 100,0 & - \\
\hline
\end{tabular}




\begin{tabular}{|c|c|c|c|c|c|c|c|c|c|c|c|}
\hline \multicolumn{12}{|c|}{$\begin{array}{c}\text { CUADRO } 16 \\
\text { EMPRESAS EXPORTADORAS POR NÚMERO DE ASALARIADOS }\end{array}$} \\
\hline & $\begin{array}{c}\text { Entre } \\
0-9\end{array}$ & $\begin{array}{l}\text { Total } \\
\%\end{array}$ & $\begin{array}{l}\text { De } \\
10 \text { a } 49\end{array}$ & $\begin{array}{c}\text { Total } \\
\%\end{array}$ & $\begin{array}{l}\mathrm{De} \\
50-249\end{array}$ & $\begin{array}{c}\text { Total } \\
\%\end{array}$ & $\begin{array}{l}\text { PYME } \\
(0-249)\end{array}$ & $\begin{array}{c}\text { Total } \\
\%\end{array}$ & $>250$ & $\begin{array}{c}\text { Total } \\
\%\end{array}$ & $\begin{array}{c}\text { Total } \\
\text { (equivalente } \\
\text { datos } \\
\text { DIRCE) }\end{array}$ \\
\hline Francia ................. & 76.096 & 64,7 & 28.599 & 24,0 & 9.610 & 8,0 & 114.305 & 97,3 & 3.229 & 2,7 & 117.534 \\
\hline Países Bajos ............................ & 100.480 & 79,7 & 18.611 & 15,0 & 5.577 & 4,0 & 124.668 & 98,9 & 1.416 & 1,1 & 126.084 \\
\hline 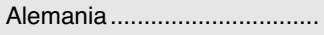 & 105.396 & 57,7 & 52.396 & 29,0 & 19.170 & 11,0 & 176.962 & 97,0 & 5.550 & 3,0 & 182.512 \\
\hline Italia & 125.403 & 65,6 & 53.649 & 28,0 & 10.349 & 5,0 & 189.401 & 99,0 & 1.861 & 1,0 & 191.262 \\
\hline 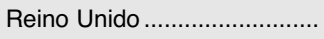 & 86.779 & 64,8 & 33.257 & 25,0 & 10.387 & 8,0 & 130.423 & 97,4 & 3.449 & 2,6 & 133.872 \\
\hline Irlanda .............. & nd & nd & nd & nd & nd & nd & nd & nd & nd & nd & 0 \\
\hline Dinamarca... & 14.770 & 64,2 & 6.081 & 26,0 & 1.715 & 7,0 & 22.566 & 98,1 & 445 & 1,9 & 23.011 \\
\hline Grecia & 9.957 & 56,8 & 5.327 & 30,0 & 1.737 & 10,0 & 17.021 & 97,2 & 498 & 2,8 & 17.519 \\
\hline Portugal....................................... & 29905 & 67,4 & 11.211 & 25,0 & 2.745 & 6,0 & 43.861 & 98,8 & 528 & 1,2 & 44.389 \\
\hline España & 62.542 & 65,7 & 23.129 & 24,0 & 7.328 & 8,0 & 92.999 & 97,8 & 2.140 & 2,2 & 95.139 \\
\hline 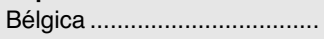 & 30.526 & 67,9 & 10.941 & 24,0 & 2.738 & 6,0 & 44.205 & 98,4 & 739 & 1,6 & 44.944 \\
\hline 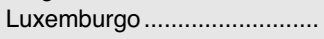 & 1.032 & 69,3 & nd & nd & 354 & 24,0 & 1.386 & 93,0 & 104 & 7,0 & 1.490 \\
\hline Suecia & 29.463 & 70,7 & 8.719 & 21,0 & 2.593 & 6,0 & 40.775 & 97,9 & 869 & 2,1 & 41.644 \\
\hline Finlandia & 9.571 & 66,9 & 3.117 & 22,0 & 1.135 & 8,0 & 13.823 & 96,6 & 485 & 3,4 & 14.308 \\
\hline 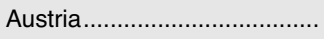 & 28.278 & 67,5 & 9.721 & 23,0 & 2.943 & 7,0 & 40.942 & 97,8 & 926 & 2,2 & 41.868 \\
\hline Malta & 540 & 58,6 & 256 & 28,0 & 97 & 11,0 & 893 & 96,9 & 29 & 3,1 & 922 \\
\hline 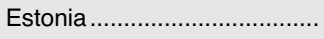 & 8.657 & 74,6 & 2.178 & 19,0 & 650 & 6,0 & 11.485 & 99,0 & 117 & 1,0 & 11.602 \\
\hline Letonia & 8.030 & 65,8 & 3.112 & 26,0 & 161 & 1,0 & 11.303 & 92,7 & 893 & 7,3 & 12.196 \\
\hline 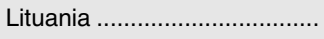 & 9.391 & 60,1 & 4.634 & 30,0 & 1.353 & 9,0 & 15.378 & 98,4 & 248 & 1,6 & 15.626 \\
\hline 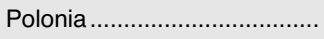 & 51.383 & 63,7 & 19.227 & 24,0 & 7.735 & 10,0 & 78.345 & 97,2 & 2.283 & 2,8 & 80.628 \\
\hline República Checa ..................... & nd & nd & nd & nd & nd & nd & nd & nd & nd & nd & nd \\
\hline 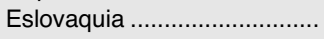 & 18.551 & 72,5 & 5.009 & 20,0 & 1.627 & 6,0 & 25.187 & 98,4 & 402 & 1,6 & 25.589 \\
\hline 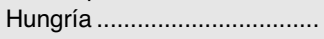 & 27.852 & 72,0 & 7.952 & 21,0 & 2.311 & 6,0 & 38.115 & 98,5 & 594 & 1,5 & 38.709 \\
\hline 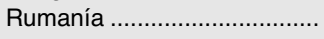 & nd & nd & nd & nd & nd & nd & nd & nd & nd & nd & nd \\
\hline 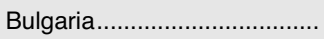 & 11.717 & 62,5 & 5.053 & 27,0 & 1.981 & 11,0 & 18.751 & 100,0 & 0 & 0,0 & 18.751 \\
\hline 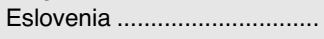 & 15.140 & 80,7 & 2.648 & 14,0 & 782 & 4,0 & 18.570 & 98,9 & 201 & 1,1 & 18.771 \\
\hline 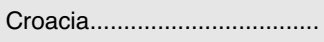 & 4.952 & 58,6 & 2.327 & 28,0 & 902 & 11,0 & 8.181 & 96,7 & 276 & 3,3 & 8.457 \\
\hline 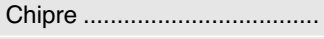 & 1.174 & 65,1 & 457 & 25,0 & 128 & 7,0 & 1.759 & 97,5 & 45 & 2,5 & 1.804 \\
\hline 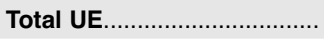 & 867.585 & 66,3 & 317.611 & 24,27 & 96.108 & 7,3 & 1.281 .304 & 97,9 & 27.327 & 2,1 & 1.308 .631 \\
\hline
\end{tabular}

sin embargo, el caso de Alemania, donde la presencia de este tramo de empresas es notablemente inferior (57,7 por 100).

España se sitúa también en la media en cuanto a la presencia de grandes empresas entre las exportadoras, con más de 250 empleados, un 2,2 por 100 frente a un 2,1 por 100 de la media de la UE-28. De nuevo vuelve a destacar Alemania, con un 3 por 100 de este tipo de empresas dentro del total de las exportadoras, aunque en este caso también alcanzan casi el 3 por 100 otras grandes economías de la UE-28 como Francia (2,7 por 100) o Reino Unido (2,6 por 100) y lo superan ampliamente Luxemburgo (7 por 100) y Letonia (7,3 por 100).

\section{Conclusiones}

A partir de los datos que elabora Aduanas de forma anual, se puede realizar una aproximación a las características de los operadores de comercio exterior en términos de números de asalariados, de actividad económica principal o de número de destinos geográficos con los que se realizan operaciones. En este artículo nos hemos centrado en los operadores que realizan exportaciones, por su mayor interés para conocer el patrón de las empresas que se animan a acceder a mercados internacionales y ver la evolución que ha tenido lugar en los últimos años, pero los datos permiten también realizar un análisis equivalente para los operadores que se dedican a importar desde el resto del mundo.

Este análisis nos permite extraer una serie de conclusiones, que a su vez pueden ser de interés a la hora de perfilar el apoyo de la Administración a la internacionalización de las empresas, como hace la Secretaría de Estado de Comercio en su Plan Estratégico de Internacionalización de la Economía Española desde 2014, que está previsto actualizar para 2015 y 2016. 
Concretamente, los datos muestran que en los últimos cuatro años se ha producido un incremento del número de operadores que realizaron actividades de exportación, y lo que es más relevante, de las empresas que lo hacen de forma regular. Este hecho puede indicar un cambio de patrón de la economía española hacia una mayor internacionalización de nuestro tejido productivo.

Se constata que las características de los operadores que realizan actividades de exportación reproducen las existentes para el conjunto del tejido español. En este sentido, casi dos terceras partes de los exportadores son microempresas (con menos de 10 asalariados), y casi la totalidad son pymes, si bien su participación en ambos casos en el total del valor exportado es muy inferior a su relevancia en términos de número de empresas.

En términos de propensión exportadora, los datos ponen de manifiesto que una reducida proporción de las microempresas declara operaciones de exportación, incrementándose significativamente cuando las empresas pasan a tener de 10 a 49 empleados, y más aún cuando pasan al siguiente tramo, entre 50 y 199 empleados. En cambio, las grandes empresas tienen una vocación exportadora muy superior. Por tanto, a efectos de fomentar la actividad exportadora, parece que la dimensión de la empresa en términos de asalariados es un factor determinante.

Desde la perspectiva sectorial, las empresas de la industria manufacturera muestran una vocación exportadora mayor, y además tienen en general una mayor presencia de grandes empresas entre las que lo hacen.
Hay una elevada concentración de las exportaciones, ya que un cuarto de las mismas es realizado por las 20 principales empresas exportadoras, si bien se ha producido una cierta reducción en esta concentración en los últimos cuatro años. La concentración es más acentuada en las exportaciones a países extracomunitarios que en las ventas a la UE, reflejando posiblemente las mayores barreras a la internacionalización para las empresas pequeñas en los destinos no tradicionales. De hecho, la mayoría de las empresas sólo realiza operaciones de exportación a un único destino, pero de reducido monto, por lo que la participación en el valor total de las exportaciones es muy superior para las pocas empresas que exportan a más de diez países.

En comparación con los países de nuestro entorno, observamos que las características de las empresas exportadoras españolas no son muy distintas a las de la media de la UE, con la misma participación mayoritaria de pymes en el total, y con una fuerte presencia de microempresas y muy reducida de grandes empresas, si bien destaca el caso de Alemania, donde este último segmento es más relevante, en detrimento de las empresas de menor dimensión.

\section{Bibliografía}

[1] DEPARTAMENTO DE ADUANAS (2015). Comercio internacional de mercancías según características de la empresa.

[2] INSTITUTO NACIONAL DE ESTADÍSTICA (2015). Directorio Central de Empresas.

[3] EUROSTAT (2015). Estadísticas de comercio por tamaño de la empresa y sector de actividad.

[4] SECRETARÍA DE ESTADO DE COMERCIO (2014). Plan Estratégico de Internacionalización de la Economía Española. 
